\title{
Risk factors for surgical site infections following open versus laparoscopic colectomies: a cohort study
}

Tomer Hoffman ${ }^{1 \dagger}$, Pnina Shitrit ${ }^{2 \dagger}$ and Michal Chowers ${ }^{1,3^{*}}$ (1)

\begin{abstract}
Background: Surgical site infections (SSIs) are among the most common healthcare-associated infections. Evaluating risk factors for SSIs among patients undergoing laparoscopic and open colorectal resections can aid in selecting appropriate candidates for each modality.

Methods: A cohort of all consecutive patients undergoing elective colorectal resections during 2008-2017 in a single center was analyzed. SSIs were prospectively assessed by infection control personnel. Patient data were collected from electronic medical records. Risk factors for SSIs were compared between patients who underwent laparoscopic and open surgeries. A multivariate analysis was performed for significant variables.

Results: During the study period, 865 patients underwent elective colorectal resection: 596 laparoscopic and 269 open surgeries. Mean age was $68.2 \pm 15.1$ years, weight $72.5 \pm 18.3 \mathrm{~kg}$ and $441(51 \%)$ were men. The most common indication for surgery was malignancy, in 767 patients (88.7\%) with inflammatory bowel diseases and diverticulitis following (4.5\% and 3.9\%, respectively). Patients undergoing laparoscopic surgery were younger, had fewer comorbidities, shorter pre-operative hospitalizations, lower risk index scores, and lower rates of SSI, compared with open surgery. Independent risk factors for SSI following laparoscopic surgery were chronic obstructive pulmonary disease [odds ratio (OR) $2.65595 \% \mathrm{Cl}(1.267,5.565)]$, risk index $\geq 2$ [OR 2.079, $95 \% \mathrm{Cl}(1.041,4.153)]$ and conversion of laparoscopic to open surgery [OR $2.05695 \% \mathrm{Cl}(1.212,3.486)]$. Independent risk factors for SSI following open surgery were immunosuppression [OR 3.378 95\% Cl $(1.071,10.655)]$, chronic kidney disease [OR $2.64395 \% \mathrm{Cl}(1.008,6.933)]$, and need for a second dose of prophylactic antibiotics [OR 2.519 95\%Cl $(1.074,5.905)]$.
\end{abstract}

Conclusions: Risk factors for SSIs differ between laparoscopic and open colorectal resections. Knowledge of specific risk factors may inform patient selection for these modalities.

Keywords: Colorectal surgery, Laparoscopic, Surgical site infection, Chronic obstructive pulmonary disease, Risk factors

\section{Background}

Surgical site infections (SSIs) are among the most common healthcare-associated infections (HAIs), accounting for approximately $20 \%$ of HAIs in the United States [1]

\footnotetext{
*Correspondence: chowersm@post.tau.ac.il

†Tomer Hoffman and Pnina Shitrit contributed equally

${ }^{1}$ Infectious Diseases Unit, Meir medical Center, Kfar-Saba, Israel

Full list of author information is available at the end of the article
}

and Europe [2]. Colorectal surgery is associated with a particularly high risk of SSI, with SSI rates ranging from 9 to $27 \%[3,4]$.

A Cochrane review found that antibiotic prophylaxis reduced the risk of SSI following colorectal surgery from 39 to $13 \%$ [5].

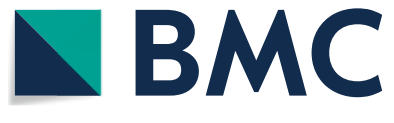

(c) The Author(s) 2021. Open Access This article is licensed under a Creative Commons Attribution 4.0 International License, which permits use, sharing, adaptation, distribution and reproduction in any medium or format, as long as you give appropriate credit to the original author(s) and the source, provide a link to the Creative Commons licence, and indicate if changes were made. The images or other third party material in this article are included in the article's Creative Commons licence, unless indicated otherwise in a credit line to the material. If material is not included in the article's Creative Commons licence and your intended use is not permitted by statutory regulation or exceeds the permitted use, you will need to obtain permission directly from the copyright holder. To view a copy of this licence, visit http://creativecommons.org/licenses/by/4.0/. The Creative Commons Public Domain Dedication waiver (http://creativecommons.org/publicdomain/zero/1.0/) applies to the data made available in this article, unless otherwise stated in a credit line to the data. 
The causative organisms of SSIs after colorectal surgery originate in the intestinal lumen, and are primarily Enterobacterales and anaerobic bacteria.

The risk for an SSI following colorectal surgery relates both to patient characteristics and to procedure-related factors. Superficial SSIs, deep SSIs and organ-space infections differ in their specific risk factors for SSIs [6].

Laparoscopy is an increasingly popular surgical approach for colorectal surgery in general and for colorectal resections in particular, as it is associated with improved post-operative morbidity, lower SSI rates and reduced post-operative mortality rates [7].

Risk factors for SSIs following laparoscopic colorectal resections are not as well described as for an open surgical approach, due to limitations of previous studies, including heterogeneous patient populations and surgical indications, limited sample sizes and inconsistent results [8-10]. In addition, data comparing risk factors for SSIs following laparoscopic and open colorectal resections in similar patient populations are lacking.

The primary objective of this cohort study was to compare the risk factors for SSIs between patients undergoing laparoscopic vs. open colorectal resections.

\section{Methods}

\section{Study design and patients}

This study was based on a prospective cohort consisting of all consecutive patients age 18 years or older who underwent elective (non-urgent) colorectal resection surgery at Meir Medical Center in Israel from January 1 , 2008 through December 31, 2017.

\section{Data collection}

During the study period, SSIs were prospectively monitored by dedicated infection control practitioners (ICP) as part of an ongoing surveillance program of post-operative colorectal patients. The surveillance included direct observation of the patient and the surgical site $72 \mathrm{~h}$ postsurgery, a phone call to patients at day 30 after surgery and assessment of patient electronic medical records, including outpatient clinic visits, and antibiotic prescription in the community.

Definition of SSIs and their classification (superficial wound infection, deep wound infection or organ-space infection) were based on CDC guidelines [11]. Thus anastomotic leaks were considered space-organ infections and were not included as a cause for SSIs.

Standardized data collection was prospectively performed throughout the surveillance period. Additional data were historically collected from electronic medical records. Data on the following parameters was collected: age, sex, comorbidities, previous abdominal surgeries, risk index [12], indication for surgery, colonic segment resected, duration of pre-operative hospitalization, surgery duration, prophylactic antibiotics, ileostomy/colostomy, conversion of laparoscopic to open surgery, SSI occurrence, microbial pathogens in wound/surgical/ drain/blood sample cultures, antibiotic therapy, re-operation, hospitalization duration, re-admission and death within 30 days of surgery.

\section{Statistical analysis}

Descriptive data of continuous and ordinal variables are presented as mean, median and standard deviation, Categorical variables are presented as percentages.

Chi-square, independent t-test and Wilcoxon ranksum tests were used to test for differences in characteristics between patient groups. Logistic regression models were used to test the association between SSI and each of the variables in the laparoscopic and open surgery groups. Variables deemed important or variables with P-values $\leq 0.1$ were eligible for multivariate regression analysis. Odds ratio values are presented, along with $95 \%$ confidence intervals (CI). Statistical significance was defined as $\mathrm{P}<0.05$. All data were analyzed using SPSS software, version 25.0 (IBM Corp. Armonk, NY, USA).

\section{Ethical considerations}

The study was approved by the Institutional Review Board of Meir Medical Center (59-17 MMC). Due to the retrospective nature of the study the need for consent was waived.

\section{Results}

Over the 10-year study period, 865 patients underwent elective colorectal resections, 596 laparoscopic surgery and 269 open surgery. The mean age was $68.2 \pm 15.1$ years, the mean weight was $72.5 \pm 18.3 \mathrm{~kg}$ and $441(51 \%)$ were men. The most common indication for surgery was malignancy, in 767 patients $(88.7 \%)$, with inflammatory bowel diseases and diverticulitis following (4.5\% and 3.9\%, respectively). A total of 319 patients (36.9\%) had undergone abdominal surgery prior to the index operation. SSIs were diagnosed in 197 patients (22.8\%), of which 109 (12.6\%) were superficial and 26 (3\%) were deep wound infections and 59 (6.8\%) were organ/space infections. The most common bacteria identified was Escherichia coli in 75 cultures, Enterococcus spp. in 29 cultures, Pseudomonas spp. in 27 cultures and Staphylococcus aureus in 7. Re-operation was performed in $52(6 \%)$ patients and 17 patients (2\%) died within 30 days of surgery.

The characteristics of the patients undergoing laparoscopic versus open surgery differed in several aspects (Table 1). They were younger, had fewer comorbidities, 
Table 1 Characteristics of patients undergoing laparoscopic versus open surgery

\begin{tabular}{|c|c|c|c|}
\hline Characteristic & $\begin{array}{l}\text { Laparoscopic } \\
\mathrm{N}=596(\%)\end{array}$ & $\begin{array}{l}\text { Open } \\
N=269 \text { (\%) }\end{array}$ & P-value \\
\hline Age, years & $67.02 \pm 15.96$ & $70.82 \pm 15.50$ & 0.001 \\
\hline Men, N (\%) & $291(48.8)$ & $150(55.8)$ & 0.059 \\
\hline Weight, kg & $73.61( \pm 18.80)$ & $70.22( \pm 16.99)$ & 0.012 \\
\hline $\mathrm{DM}$ & $137(23)$ & $77(28.6)$ & 0.075 \\
\hline CVD & $124(20.8)$ & $71(26.4)$ & 0.069 \\
\hline CKD & $37(6.2)$ & $22(8.2)$ & 0.287 \\
\hline COPD & $38(6.4)$ & $28(10.4)$ & 0.039 \\
\hline Immuno-suppression & $29(4.9)$ & $15(5.6)$ & 0.660 \\
\hline Malignancy & $456(76.5)$ & $218(81.0)$ & 0.137 \\
\hline $\mathrm{IBD}$ & $28(4.7)$ & $22(8.2)$ & 0.004 \\
\hline Prior surgery & $198(33.2)$ & $121(45)$ & 0.001 \\
\hline Pre-op hospital days & $1.6 \pm 2.33$ & $2.52 \pm 4.23$ & $<0.001$ \\
\hline Rectal surg & $83(13.9)$ & $52(19.3)$ & 0.043 \\
\hline Risk Index & & & 0.008 \\
\hline 0 & 173 & 81 & \\
\hline 1 & 328 & 124 & \\
\hline$\geq 2$ & 93 & 64 & \\
\hline Surgery duration > 75\% & $331(56.1)$ & $103(38.6)$ & $<0.001$ \\
\hline Stoma created & $49(8.2)$ & $42(15.6)$ & 0.001 \\
\hline Appropriate prophylaxis & $336(67.7)$ & $114(47.7)$ & $<0.001$ \\
\hline $2^{\text {nd }}$ antibiotic dose & $62(10.4)$ & $28(10.4)$ & 0.998 \\
\hline SSI & $110(18.5)$ & $87(32.3)$ & $<0.001$ \\
\hline hospital days & $7.94 \pm 9.09$ & $13.99 \pm 25.27$ & $<0.001$ \\
\hline Reoperation & $23(3.9)$ & $29(10.8)$ & $<0.001$ \\
\hline Readmission & 69 (11.6) & $49(18.2)$ & 0.008 \\
\hline Mortality & $7(1.2)$ & $10(3.7)$ & 0.013 \\
\hline
\end{tabular}

$D M$ diabetes mellitus; $C V D$ cardiovascular disease; $C K D$ chronic kidney disease, COPD congestive obstructive pulmonary disease; IBD irritable bowel disease; SSI surgical site infection

had shorter hospital stays prior to surgery, had a lower risk index scores and, as expected, fewer SSIs.

We investigated risk factors for SSIs for each surgical modality (Table 2).

Risk factors for SSIs following laparoscopic surgeries were chronic kidney disease (CKD), chronic obstructive pulmonary disease (COPD), and diabetes mellitus (DM), high risk index score, need for a second intraoperative prophylactic antibiotic dose, and conversion of laparoscopic surgery to open surgery. We also included age, sex and weight in the regression analysis. Independent risk factors for infection following laparoscopic surgeries found in multivariate regression analysis were: COPD, OR 2.655, 95\% CI $(1.267,5.565)$; Risk index $\geq 2$, OR $2.079,95 \%$ CI $(1.041,4.153)$; and conversion to open surgery, OR $2.056,95 \% \mathrm{CI}(1.212,3.486)$.
Risk factors for SSI following open surgeries were CKD, rectal surgery, and the need for a second intra-operative prophylactic antibiotic dose. The regression model included age, sex, weight, immunosuppression, cardiovascular disease (CVD), COPD, and risk index. Independent risk factors for SSIs following open surgeries found in multivariate regression analysis were: immunosuppression, OR 3.378, 95\% CI (1.071, 10.655); CKD, OR $2.64395 \%$ CI $(1.008,6.933)$; and the need for a second intra-operative prophylactic antibiotic dose, OR 2.519, $95 \%$ CI $(1.074,5.905)$.

\section{Discussion}

In this study of 865 patients undergoing elective colorectal surgery, we found different risk factors for SSIs among patients undergoing laparoscopic vs. open colorectal resections. Focusing on basic patient characteristics, COPD was a risk factor for an SSI following laparoscopic surgery but not following open surgery, whereas CKD and immunosuppression were risk factors following open surgery only. Many studies focused on modifiable risk factors, such as prophylactic antibiotics, surgical techniques, and bowel preparation. Patient characteristics are not subject to change but optimal patient selection for each surgical modality may affect the risk of infection.

Laparoscopic colorectal resection has become increasingly popular in the field of colorectal surgery, increasing in incidence from 15\% of all colorectal resections in 2007 [13] to 56\% in a study published in 2019. This rise in popularity is in part related to lower complication rates, including lower rates of SSIs, seen in laparoscopic surgery [14].

Laparoscopic surgery has been found safe and superior to open surgery in numerous patient outcomes and in a variety of patient populations. In our study, laparoscopic surgery was selected for most patients (69\%). The research question we sought to answer was whether there were specific patient populations for which open surgery would be preferable with regard to the risk of SSI. Chronic obstructive pulmonary disease was found to be an independent risk factor for SSIs following laparoscopic but not open colorectal resection. Laparoscopic surgery, although minimally invasive, requires the creation of a pneumoperitoneum, thus reducing important pulmonary function parameters, such as dynamic compliance and functional residual capacity, which increases the risk of hypoxemia [15].

Laparoscopic surgery might increase the risk for an SSI among patients with COPD. In a study by Liao et al. patient outcomes following laparoscopic cholecystectomies were worse in 3954 COPD patients compared to age-and gender-matched non-COPD patients. They found increased rates of intensive care unit admission, 
Table 2 Risk-factors for surgical site infection (SSI) with laparoscopic and open surgeries

\begin{tabular}{|c|c|c|c|c|c|c|}
\hline \multirow[t]{2}{*}{ Risk-factor } & \multicolumn{3}{|c|}{ Laparoscopic (596) } & \multicolumn{3}{|l|}{ Open (269) } \\
\hline & $\begin{array}{l}S S I \\
N=110(\%)\end{array}$ & No SSI N=486(\%) & P-value & $\begin{array}{l}\mathrm{SSI} \\
\mathrm{N}=87(\%)\end{array}$ & $\begin{array}{l}\text { No SSI } \\
\mathrm{N}=182 \text { (\%) }\end{array}$ & P-value \\
\hline Age, years & $68.1 \pm 14.6$ & $66.8 \pm 15.5$ & 0.414 & $70.7 \pm 14.1$ & $70.9 \pm 14.8$ & 0.924 \\
\hline Men, N & $60(54.5)$ & $231(47.5)$ & 0.184 & $55(63.2)$ & $96(52.2)$ & 0.089 \\
\hline Weight, kg & $76.5 \pm 23.1$ & $73.0 \pm 17.6$ & 0.133 & $72.4 \pm 17.8$ & $69.2 \pm 16.6$ & 0.149 \\
\hline $\mathrm{DM}$ & $33(30)$ & $104(21.4)$ & 0.053 & $21(24.1)$ & $56(30.8)$ & 0.26 \\
\hline CVD & $25(22.7)$ & $99(20.4)$ & 0.582 & $29(33.3)$ & $42(23.1)$ & 0.074 \\
\hline CKD & $12(10.9)$ & $25(5.1)$ & 0.024 & $12(13.8)$ & $10(5.5 \%)$ & 0.02 \\
\hline COPD & $14(12.7)$ & $24(4.9)$ & 0.003 & $13(14.9)$ & $15(8.2)$ & 0.092 \\
\hline Immunosuppression & $8(7.3)$ & $21(4.3)$ & 0.194 & $8(9.2)$ & $7(3.8)$ & 0.074 \\
\hline Malignancy & $84(76.4)$ & $372(76.5)$ & 0.968 & $66(75.9)$ & $152(83.5)$ & 0.134 \\
\hline $\mathrm{IBD}$ & $7(6.4)$ & $21(4.3)$ & 0.153 & $9(10.3)$ & $13(7.1)$ & 0.37 \\
\hline Prior surgery & $34(30.9)$ & $164(33.7)$ & 0.569 & $41(47.1)$ & $80(44)$ & 0.625 \\
\hline Pre-op hospital days & $1.9 \pm 2.9$ & $1.5 \pm 2.2$ & 0.253 & $2.9 \pm 5.2$ & $2.4 \pm 4.0$ & 0.40 \\
\hline Rectal surg & $16(14.5)$ & $67(13.8)$ & 0.835 & $23(26.4)$ & $29(15.9)$ & 0.041 \\
\hline Risk Index & & & 0.005 & & & 0.082 \\
\hline 0 & 20 & 155 & & 23 & 58 & \\
\hline 1 & 65 & 263 & & 36 & 88 & \\
\hline$\geq 2$ & 25 & 68 & & 28 & 36 & \\
\hline Surgery duration $>75 \%$ & $59(63.9)$ & $262(54.4)$ & 0.071 & $40(46.5)$ & $63(34.8)$ & 0.066 \\
\hline Stoma created & $13(11.8)$ & $36(7.4)$ & 0.128 & $17(19.5)$ & $25(13.7)$ & 0.220 \\
\hline Converted to open & $27(24.5)$ & $63(13)$ & 0.002 & & & \\
\hline Appropriate prophylaxis & $86(81.1)$ & $366(76.3)$ & 0.279 & $58(67.4)$ & $99(57.6)$ & 0.125 \\
\hline Second antibiotic dose & $18(16.4)$ & $44(9.1)$ & 0.023 & $15(17.2)$ & $13(7.1)$ & 0.011 \\
\hline Post-op hospital days & $13 \pm 18.9$ & $6.7 \pm 3.6$ & $<0.001$ & $20.0 \pm 23.2$ & $11.1 \pm 25.8$ & 0.005 \\
\hline Reoperation & $17(15.5)$ & $6(1.2)$ & $<0.001$ & $23(26.4)$ & $6(3.3)$ & $<0.001$ \\
\hline Readmission & $34(30.9)$ & $35(7.2)$ & $<0.001$ & $21(24.1)$ & $28(15.4)$ & 0.082 \\
\hline Mortality & $2(1.8)$ & $5(1)$ & 0.488 & $8(9.2)$ & $2(1.1)$ & 0.002 \\
\hline
\end{tabular}

$D M$ diabetes mellitus; $C V D$ cardiovascular disease; $C K D$ chronic kidney disease, COPD congestive obstructive pulmonary disease; IBD irritable bowel disease

longer durations of mechanical ventilation and hospitalization, and higher mortality rates. SSIs were not assessed in that study [16]. Other studies identified COPD as risk factor for SSIs in a mixed patient population undergoing colorectal surgery $[17,18]$, but the contribution of this risk factor for infection in the different surgical modalities could not be assessed. Drosdeck et al. did not find COPD to be a risk factor for SSIs in a study of 400 patients undergoing laparoscopic colorectal surgery. Of note, inclusion criteria in this study were different, and all patients whose surgeries were converted to open surgeries were excluded [19]. A large study of 4397 COPD patients compared complications of laparoscopic versus open colorectal surgery. In that study, laparoscopic surgery improved most surgical outcomes including ventilator requirement and SSIs by almost $50 \%$. Of note, preoperative steroid use was more frequent in the open surgery cohort, as well as partially-dependent functional status, perhaps favoring the laparoscopic surgery group in relation to the risk of SSI [20]. An important factor in reconciling our results with those of Sujatha-Bhaskar et al. [20] is that the COPD grade and severity were not assessed in either study, possibly resulting in inclusion of significantly heterogeneous COPD patient populations, making comparison more difficult. A study with a more accurate assessment of COPD severity is needed before any conclusions can be drawn.

In our study, patients who had open surgery were older, had more comorbidities and were more likely to have undergone prior abdominal surgeries. We observed a more complex clinical course in patients undergoing open surgeries, with longer hospital stays and increased re-admission, re-operation and mortality rates. Immunosuppression and CKD were independent risk factors for SSIs following open but not laparoscopic surgery. Recovery time and hospital stays are shorter after laparoscopic surgeries, an effect found in patients with malignancies as well [13]. With regard to the risk of infection, 
immunosuppressed patients might benefit most from shorter hospital stays, which are observed more often following laparoscopic surgery.

Advanced age per se should not be considered an indication for open surgery. In a meta-analysis comparing laparoscopic and open surgeries in an elderly population, overall morbidity, as well as cardiovascular complications were lower after laparoscopic surgery [21, 22].

Other independent risk factors for SSIs included conversion of laparoscopic surgery to open surgery and the need for a second intra-operative prophylactic antibiotic dose in open surgeries; both are markers of a more complicated surgical course. Although this information is only available post-operatively, it may still serve as an indication for increased vigilance in search of infection among post-operative patients.

This study had several limitations. It was a single center study and some of the data were collected retrospectively from patient records. Body mass index, a known risk factor for SSIs, was missing from many records, forcing us to use weight as a surrogate marker. Of note, SSI, our major outcome, was assessed prospectively in real-time by experienced ICP.

\section{Conclusion}

Patient characteristics are known, non-modifiable risk factors for SSIs. We suggest that risk factors for SSIs differ between laparoscopic and open colorectal resections, and that knowledge of specific risk factors for SSIs may inform selection of the appropriate surgical modality for every patient.

\section{Abbreviations}

SSIs: Surgical site infections; OR: Odds ratio; ICP: Infection control practitioners; CKD: Chronic kidney disease; COPD: Chronic obstructive pulmonary disease; DM: Diabetes mellitus; CVD: Cardiovascular disease.

\section{Acknowledgements}

We thank Faye Schreiber for editorial assistance.

\begin{abstract}
Authors' contributions
TH: data collection, data analysis, drafted the manuscript. PS: conception and design of study MC: interpretation of data, substantial revision of manuscript. All authors have approved the submitted version. All authors have agreed both to be personally accountable for the author's own contributions and to ensure that questions related to the accuracy or integrity of any part of the work, even ones in which the author was not personally involved, are appropriately investigated, resolved, and the resolution documented in the literature.
\end{abstract}

\section{Funding}

No funding was received for this work.

\section{Availability of data and materials}

Data will be available per request (chowersm@post.tau.ac.il).

\section{Declarations}

Ethics approval and consent to participate

This study was approved by the Meir Medical Center ethics committee, reference number 59-17 MMC. Due to the retrospective nature of the study consent of participant was waived by the committee.

\section{Consent for publication}

Not applicable.

\section{Competing interests}

No conflict of interests for any of the authors.

\section{Author details}

${ }^{1}$ Infectious Diseases Unit, Meir medical Center, Kfar-Saba, Israel. ${ }^{2}$ Infection Control Unit, Meir medical Center, Kfar-Saba, Israel. ${ }^{3}$ Sackler Medical School, Tel-Aviv University, Tel-Aviv, Israel.

Received: 6 June 2021 Accepted: 15 October 2021

Published online: 25 October 2021

\section{References}

1. Magill SS, Edwards JR, Bamberg W, Beldavs ZG, Dumyati G, Kainer MA, Lynfield R, Maloney M, McAllister-Hollod L, Nadle J, et al. Multistate pointprevalence survey of health care-associated infections. N Engl J Med. 2014:370(13):1198-208.

2. European Centre for Disease Prevention and Control. Point prevalence survey of healthcare-associated infections and antimicrobial use in European acute care hospitals 2011-2012. Stockholm: ECDC; 2013.

3. European Centre for Disease Prevention and Control. Surgical site infections. In: ECDC. Annual epidemiological report for 2016. Stockholm: ECDC; 2018. https://www.ecdc.europa.eu/en/publications-data/healt hcare-associated-infections-surgical-site-infections-annual-0. accessed May 2021

4. Bratzler DW, Dellinger EP, Olsen KM, Perl TM, Auwaerter PG, Bolon MK, Fish DN, Napolitano LM, Sawyer RG, Slain D, et al. Clinical practice guidelines for antimicrobial prophylaxis in surgery. Am J Health Syst Pharm. 2013;70(3):195-283

5. Nelson RL, Gladman E, Barbateskovic M. Antimicrobial prophylaxis for colorectal surgery. Cochrane Database Syst Rev. 2014;5:CD001181.

6. Segal CG, Waller DK, Tilley B, Piller L, Bilimoria K. An evaluation of differences in risk factors for individual types of surgical site infections after colon surgery. Surgery. 2014;156(5):1253-60.

7. Kang CY, Chaudhry OO, Halabi WJ, Nguyen V, Carmichael JC, Stamos MJ, Mills S. Outcomes of laparoscopic colorectal surgery: data from the Nationwide Inpatient Sample 2009. Am J Surg. 2012;204(6):952-7.

8. Kurmann A, Vorburger SA, Candinas D, Beldi G. Operation time and body mass index are significant risk factors for surgical site infection in laparoscopic sigmoid resection: a multicenter study. Surg Endosc. 2011;25(11):3531-4.

9. Kvasnovsky C, Adams K, Sideris M, Laycock J, Haji A, Haq A, Nunoo-Mensah J, Papagrigoriadis S. Elderly patients have more infectious complications following laparoscopic colorectal cancer surgery. Colorectal Dis. 2016;18(1):94-100.

10. Yamamoto S, Fujita S, Akasu T, Ishiguro S, Kobayashi Y, Moriya Y. Wound infection after elective laparoscopic surgery for colorectal carcinoma. Surg Endosc. 2007;21(12):2248-52.

11. Mangram AJ, Horan TC, Pearson ML, Silver LC, Jarvis WR. Guideline for Prevention of Surgical Site Infection, 1999. Centers for Disease Control and Prevention (CDC) Hospital Infection Control Practices Advisory Committee. Am J Infect Control. 1999;27(2):97-132.

12. Pastor C, Baek J-H, Varma MG, Kim E, Indorf LA, Garcia-Aguilar J. Validation of the risk index category as a predictor of surgical site infection in elective colorectal surgery. Dis Colon Rectum. 2010;53(5):721-7.

13. Hinojosa MW, Murrell ZA, Konyalian VR, Mills S, Nguyen NT, Stamos MJ. Comparison of laparoscopic vs open sigmoid colectomy for benign and malignant disease at academic medical centers. J Gastrointest Surg. 2007:11(11):1423-9. 
14. Wang Z, Chen J, Wang P, Jie Z, Jin W, Wang G, Li J, Ren J. Surgical site infection after gastrointestinal surgery in China: a multicenter prospective study. J Surg Res. 2019;240:206-18.

15. Salihoglu Z, Demiroluk S, Baca B, Ayan F, Kara H. Effects of pneumoperitoneum and positioning on respiratory mechanics in chronic obstructive pulmonary disease patients during Nissen fundoplication. Surg Laparosc Endosc Percutan Tech. 2008;18(5):437-40.

16. Liao K-M, Tseng C-J, Chen Y-C, Wang J-J, Ho C-H. Outcomes of laparoscopic cholecystectomy in patients with and without COPD. Int J Chron Obstruct Pulmon Dis. 2019;14:1159.

17. Kamboj M, Childers T, Sugalski J, Antonelli D, Bingener-Casey J, Cannon J, Cluff K, Davis KA, Dellinger EP, Dowdy SC, et al. Risk of Surgical Site Infection (SSI) following Colorectal Resection Is Higher in Patients With Disseminated Cancer: An NCCN Member Cohort Study. Infect Control Hosp Epidemiol. 2018;39(5):555-62.

18. Sutton E, Miyagaki H, Bellini G, Shantha Kumara HM, Yan X, Howe B, Feigel A, Whelan RL. Risk factors for superficial surgical site infection after elective rectal cancer resection: a multivariate analysis of 8880 patients from the American College of Surgeons National Surgical Quality Improvement Program database. J Surg Res. 2017;207:205-14.
19. Drosdeck J, Harzman A, Suzo A, Arnold M, Abdel-Rasoul M, Husain S. Multivariate analysis of risk factors for surgical site infection after laparoscopic colorectal surgery. Surg Endosc. 2013;27(12):4574-80.

20. Sujatha-Bhaskar S, Alizadeh RF, Inaba CS, Koh CY, Jafari MD, Mills SD, Carmichael JC, Stamos MJ, Pigazzi A. Respiratory complications after colonic procedures in chronic obstructive pulmonary disease: does laparoscopy offer a benefit? Surg Endosc. 2018;32(3):1280-5.

21. Antoniou SA, Antoniou GA, Koch OO, Pointner R, Granderath FA. Laparoscopic colorectal surgery confers lower mortality in the elderly: a systematic review and meta-analysis of 66,483 patients. Surg Endosc. 2015;29(2):322-33.

22. Fujii S, Tsukamoto M, Fukushima Y, Shimada R, Okamoto K, Tsuchiya T, Nozawa K, Matsuda K, Hashiguchi Y. Systematic review of laparoscopic vs open surgery for colorectal cancer in elderly patients. World J Gastrointest Oncol. 2016;8(7):573-82.

\section{Publisher's Note}

Springer Nature remains neutral with regard to jurisdictional claims in published maps and institutional affiliations.
Ready to submit your research? Choose BMC and benefit from:

- fast, convenient online submission

- thorough peer review by experienced researchers in your field

- rapid publication on acceptance

- support for research data, including large and complex data types

- gold Open Access which fosters wider collaboration and increased citations

- maximum visibility for your research: over $100 \mathrm{M}$ website views per year

At BMC, research is always in progress.

Learn more biomedcentral.com/submissions 